\title{
МОДЕЛИ АНТИБИОТИКОРЕЗИСТЕНТНОСТИ САЛЬМОНЕЛЛ
}

\author{
А.М. Мендыбаева, магистр ветеринарных наук, докторант \\ P.М. Рыщанова, доктор $\mathrm{PhD}$, асс. профессор \\ P.O. Сеилханова, магистрант \\ Костанайский региональный университет им. А. Байтурсынова \\ E-mail: jks1992@mail.ru
}

Ключевые слова: антибиотикорезистентность, Salmonella, продукты животного происхождения, множественная лекарственная устойчивость, паттерны резистентности.

Реферат. Устойчивость к противомикробным препаратам является глобальной проблемой не только ветеринарии, но и общественного здравоохранения. Особые опасения вызывают резистентные микроорганизмы, передаюшиеся через пищевую ичепь. Сальмонелль являются основными возбудителями пищевых инфекиий зоонозного происхождения. Настоящее исследование направлено на изучение антибиотикорезистентности бактерий рода Salmonella, выделенных на территории Северного региона Казахстана. Всего было выделено и идентифицировано 137 изолятов сальмонелл, среди которых преобладали серотипы S. enteritidis (52,55\%) и S. typhymurium (22,63\%). Из них 110 изолятов сальмонелл проявляли устойчивость к антибактериальным препаратам, причём 70 \% были резистентны к фурадонину (77/110), 65,5% к тетраииклину (72/110), 52,7 \% - к налидиксовой кислоте (58/110). Все изучаемые изоляты были чувствительны к гентамицину. Изоляты сальмонелл обладали высоким уровнем устойчивости к препаратам группы нитрофуранов, являющихся критически важными препаратами по данным Всемирной организации здравоохранения (ВОЗ). Изоляты сальмонелл проявляли множественную резистентность. Большинство сальмонелл были резистентны к 3 и 4 группам антибактериальных препаратов, где наиболее частой моделью антибиотикорезистентности была модель «тетрациклины + фторхинолоны + хинолоны + нитрофураныл. Среди вылделенных изолятов обнаружено 12 изолятов, обладающих экстремальным уровнем резистентности к антибактериальным препаратам.

Salmonella относится к роду грамотрицательных палочек семейства Enterobacteriaceae, и в пределах двух видов - Salmonella bongori и Salmonella enterica на сегодняшний день идентифицировано более 2600 серотипов [1].

Сальмонеллез широко распространен во многих странах мира и занимает значительный удельный вес среди инфекционных болезней. Заболевание представляет собой большую ветеринарную и медицинскую проблему в связи с опасностью заражения человека от больных животных и через пищевую цепь. По данным референс-центра по сальмонеллезам и глобального десятилетнего мониторинга ВО3 за пищевыми инфекциями, 47 \% вспышек инфекций в мире относится к сальмонеллезам [2, 3].

Широкое применение антибактериальных препаратов для лечения и профилактики инфекционных заболеваний, а также в качестве стимуляторов роста в системе интенсивного животноводства посредством естественного отбора привело к распространению устойчивых микроорганизмов [4]. Устойчивые к антибактериальным препаратам микроорганизмы могут передаваться человеку через окружающую среду, при прямом контакте, а самое главное, через продукты животного и растительного происхождения [5].

Целью исследований явилось изучение моделей антибиотикорезистентности сальмонелл, циркулирующих на территории Костанайской области.

Исследования проводились на базе Научно-исследовательского института прикладной биотехнологии Костанайского регионального университета им. А. Байтурсынова. 
В период с 2018 по 2020 г. было отобрано 2890 образцов патологического материала от животных и птицы, продукции животного происхождения в точках розничной торговли Костанайской области.

Микробиологический анализ. Выделение и идентификация сальмонелл проводились согласно методическим указаниям «Лабораторная диагностика сальмонеллезов, обнаружение сальмонелл в пищевых продуктах и объектах окружающей среды» [6].

Выделение бактерий проводили с использованием жидких селективных сред предварительного обогащения и посева на плотные дифференциально-диагностические среды. Учет характерных колоний проводили после 24-часовой инкубации при температуре $+37{ }^{\circ} \mathrm{C}$ или при необходимости после 48 ч. Типичные колонии отсевали для дальнейшей биохимической идентификации и серотипирования.

Серотипирование. Серотипирование сальмонелл проводили согласно схеме КауфманаУайта методом агглютинации на предметном стекле с использованием О- и Н-антигенных сывороток [6].

Секвенирование по Сэнгеру. Для подтверждения таксономического положения выделенных изолятов сальмонелл проводили секвенирование по методу Сэнгера. В качестве генетического маркера был использован участок гена $16 \mathrm{~S}$ рРНК. В работе применялась пара универсальных праймеров: 8F(5'-AGAGTTTGATCCTGGCTCAG-3') [7] и 806R(5'GGACTACCAGGGTATCTAAT-3') [8].

Идентифицированные изоляты сальмонелл тестировали на чувствительность к антибактериальным препаратам.

Определение чувствительности к антибактериальным препаратам. Тестирование чувствительности к антибиотикам проводили диско-диффузным методом [9] по Кирби-Бауэру. В тестировании использовали 15 дисков с антибактериальными препаратами следующих фармакологических групп: $\beta$-лактамы (ампициллин - 10 мкг; амоксициллин - 25 мкг; цефоперазон - 75 мкг; цефокситин - 30 мкг; цефподоксим - 10 мкг), аминогликозиды (стрептомицин 10 мкг; канамицин - 30 мкг; неомицин - 30 мкг; гентамицин - 120 мкг), амфениколы (левомицетин - 30 мкг), тетрациклины (тетрациклин - 30 мкг; доксициклин - 30 мкг), фторхинолоны (энрофлоксацин - 5 мкг; ципрофлоксацин - 5 мкг; норфлоксацин - 10 мкг; офлоксацин - 5 мкг), хинолоны (налидиксовая кислота - 30 мкг), сульфаниламиды (сульфаметокзол с триметопримом - 1,25/23,75 мкг), нитрофураны (фуразолидон - 300 мкг; фурадонин - 300 мкг).

Изоляты были классифицированы как устойчивые (R), чувствительные (S) и промежуточные (I) согласно рекомендациям EUCAST [10], CLSI [11] и МУК 4.2.1890 «Определение чувствительности микроорганизмов к антибактериальным препаратам» [9] в зависимости от антибиотика и его концентрации. В качестве контроля использовался эталонный штамм S. enteritidis TA 98 PКМ (согласно паспорту, штамм резистентен к ампициллину). Изоляты, устойчивые к трем и более классам антибактериальных препаратов, считали полирезистентными.

Статистическая обработка данных проводилась с помощью пакета MS Excel.

Всего за период с 2018 по 2020 г. было исследовано 137 изолятов сальмонелл (табл. 1), выделенных из продуктов животного происхождения и патологического материала. Выделенные изоляты были охарактеризованы методами биохимической идентификации и серотипированием. Таксономическое положение изолятов подтверждено секвенированием по Сэнгеру.

Преобладающее количество сальмонелл принадлежало к подвиду Enterica, серогруппе D, серотипу enteritidis - 52,55 \%; 22,63 \% изолятов относились к подвиду Enterica, серогруппе А, серотипу typhymurium. По некоторым данным [12-14], серовары enteritidis и typhymurium являются основными возбудителями зоонозного сальмонеллеза, поражающими людей. Остальные серотипы выделялись намного реже: S. paratyphi $C-5,11 \%$, S. dublin $-4,38$, S. cholerae suis - 
3,65, S. abortus equi-3,65, S. blegdam - 2,92, S. derby - 2,19\%. Серотипы S. tenessee, S. moscow и $S$. IIIc $4 p$ составили менее $1 \%$ выделенных изолятов $(0,73 \%)$.

По результатам тестирования антибиотикорезистентности, из 137 выделенных изолятов сальмонелл 110 были резистентны к одному и более антибактериальному препарату, 27 изолятов были чувствительны ко всем исследуемым группам антибиотиков.

Таблииа 1

Количество выделенных изолятов сальмонелл по годам

\begin{tabular}{|c|c|c|c|c|c|c|}
\hline Серотип & 2018 г. & 2019 г. & 2020 г. & Всего & Среднее \pm SD & $\%$ \\
\hline S. enteritidis & 23 & 31 & 18 & 72 & $24,00 \pm 6,56$ & 52,55 \\
\hline S. typhymurium & 18 & 2 & 11 & 31 & $10,33 \pm 8,02$ & 22,63 \\
\hline S. dublin & 2 & & 4 & 6 & $2,00 \pm 2,00$ & 4,38 \\
\hline S. cholerae suis & 5 & & & 5 & $1,66 \pm 2,89$ & 3,65 \\
\hline S. abortus equi & 5 & & & 5 & $1,66 \pm 2,89$ & 3,65 \\
\hline S. IIIc4p & & 1 & & 1 & $0,33 \pm 0,58$ & 0,73 \\
\hline S. paratyphi C & & 4 & 3 & 7 & $2,33 \pm 2,08$ & 5,11 \\
\hline S. tshiongwe & & 1 & & 1 & $0,33 \pm 0,58$ & 0,73 \\
\hline S. blegdam & & 2 & 2 & 4 & $1,33 \pm 1,15$ & 2,92 \\
\hline S. derby & & 1 & 2 & 3 & $1,00 \pm 1,00$ & 2,19 \\
\hline S. tenessee & & 1 & & 1 & $0,33 \pm 0,58$ & 0,73 \\
\hline S. moscow & & 1 & & 1 & $0,33 \pm 0,58$ & 0,73 \\
\hline Всего & 53 & 44 & 40 & 137 & & 100 \\
\hline
\end{tabular}

Устойчивость изолятов сальмонелл к антибактериальным препаратам

\begin{tabular}{|c|c|c|}
\hline $\begin{array}{c}\text { Группа антибактериаль- } \\
\text { ных препаратов }\end{array}$ & Препарат & $\begin{array}{c}\text { Количество изолятов сальмонелл, } \\
\text { устойчивых к АБП }\end{array}$ \\
\hline \multirow{4}{*}{ Аминогликозиды } & Стрептомицин & 12 \\
\cline { 2 - 3 } & Канамицин & 5 \\
\cline { 2 - 3 } & Неомицин & 4 \\
\cline { 2 - 3 } & Гентамицин & 16 \\
\hline \multirow{4}{*}{ з-лактамы } & Ампициллин & 14 \\
\cline { 2 - 3 } & Амоксициллин & 12 \\
\cline { 2 - 3 } & Цефоперазон & 17 \\
\cline { 2 - 3 } & Цефокситин & 25 \\
\cline { 2 - 3 } & Цефподоксим & 6 \\
\hline Амфениколы & Левомицетин & 72 \\
\hline Тетрациклины & Тетрациклин & 40 \\
\hline \multirow{4}{*}{ Фторхинолоны } & Доксициклин & 27 \\
\cline { 2 - 3 } & Энрофлоксацин & 14 \\
\cline { 2 - 3 } & Ципрофлоксацин & 15 \\
\cline { 2 - 3 } & Норфлоксацин & 34 \\
\cline { 2 - 3 } & Офлоксацин & 58 \\
\hline Хинолоны & Налидиксовая кислота & 10 \\
\hline Сульфаниламиды & Сульфаметокзол с триметопримом & 49 \\
\hline Нитрофураны & Фуразолидон & 77 \\
\cline { 2 - 3 } & Фурадонин & 0 \\
\hline
\end{tabular}


Как показано в табл. 2, наибольшее количество изолятов сальмонелл были резистентны к фурадонину (77/110, 70 \%), тетрациклину (72/110, 65,6 \%), налидиксовой кислоте (58/110, $52,7 \%$ ), а также к фуразолидону (49/110, 44,5 \%), доксициклину $(40 / 110,36,4 \%)$, офлоксацину (34/110, 30,9 \%), энрофлоксацину (27/110, 24,5 \%), цефподоксиму $(25 / 110,22,7$ \%), цефокситину (17/110, 15,5 \%), ампициллину (16/110, 14,5 \%), норфлоксацину (15/110, 13,6 \%). Показатель устойчивости к остальным антибиотикам был $\leq 10 \%$. Все изучаемые изоляты были чувствительны к гентамицину.

Настоящие исследования показали наличие высокого уровня резистентности к группам нитрофуранов и тетрациклинов среди выделенных изолятов S. enterica, что согласуется с данными, полученными рядом авторов [14, 15].

Повышенный уровень устойчивости к препаратам данных групп предполагает, что они широко используются при лечении энтеробактериальных инфекций как у животных, так и у людей. Это может быть связано также с неконтролируемым или чрезмерным использованием данных препаратов. Кроме того, не последнюю роль в распространении устойчивости играет горизонтальный перенос генов резистентности [16].

Таблииа 3

Структура устойчивости выделенных изолятов сальмонелл к антибактериальным препаратам

\begin{tabular}{|c|c|c|c|}
\hline № ח/П & Группы & \multicolumn{2}{|c|}{$\begin{array}{c}\text { Распространенность, } \mathrm{n} \\
(\%)\end{array}$} \\
\hline 1 & 2 & \multicolumn{2}{|c|}{3} \\
\hline \multirow[t]{4}{*}{1} & Аминогликозиды & $1(0,89)$ & \multirow[t]{4}{*}{$16(14,3)$} \\
\hline & Нитрофураны & $9(8)$ & \\
\hline & Тетрациклины & $2(7,14)$ & \\
\hline & Сульфаниламиды & $4(3,57)$ & \\
\hline \multirow[t]{7}{*}{2} & $\beta$-лактамы + тетрациклины & $6(5,36)$ & \multirow{7}{*}{$\begin{array}{c}17(15,2) \\
0\end{array}$} \\
\hline & Тетрациклины + сульфаниламиды & $1(0,89)$ & \\
\hline & Тетрациклины + нитрофураны & $4(3,57)$ & \\
\hline & Тетрациклины + фторхинолоны & $1(0,89)$ & \\
\hline & Фторхинолоны + хинолоны & $1(0,89)$ & \\
\hline & $\beta$-лактамы + фторхинолоны & $1(0,89)$ & \\
\hline & Хинолоны + нитрофураны & $3(2,68)$ & \\
\hline \multirow[t]{9}{*}{3} & $\beta$-лактамы + тетрациклины + фторхинолоны & $2(1,78)$ & \multirow[t]{9}{*}{$22(19,6)$} \\
\hline & $\beta$-лактамы + тетрациклины + нитрофураны & $6(5,36)$ & \\
\hline & $\beta$-лактамы + тетрациклины + аминогликозиды & $1(0,89)$ & \\
\hline & $\beta$-лактамы + тетрациклины + амфениколы & $1(0,89)$ & \\
\hline & $\beta$-лактамы + тетрациклины + аминогликозиды & $1(0,89)$ & \\
\hline & Тетрациклины + аминогликозиды + фторхинолоны & $1(0,89)$ & \\
\hline & Тетрациклины + хинолоны + нитрофураны & $1(0,89)$ & \\
\hline & Тетрациклины + фторхинолоны + нитрофураны & $1(0,89)$ & \\
\hline & Фторхинолоны + хинолоны + нитрофураны & $8(7,14)$ & \\
\hline \multirow[t]{4}{*}{4} & $\beta$-лактамы + тетрациклины + фторхинолоны + хинолоны & $5(4,46)$ & \multirow[t]{4}{*}{$32(28,6)$} \\
\hline & $\beta$-лактамы + тетрациклины + фторхинолоны + аминогликозиды & $1(0,89)$ & \\
\hline & $\beta$-лактамы + тетрациклины + аминогликозиды + нитрофураны & $2(1,78)$ & \\
\hline & $\beta$-лактамы + тетрациклины + аминогликозиды + амфениколы & $1(0,89)$ & \\
\hline
\end{tabular}




\begin{tabular}{|c|c|c|c|}
\hline & & \multicolumn{2}{|c|}{ Окончание табл. 3} \\
\hline 1 & 2 & \multicolumn{2}{|c|}{3} \\
\hline & $\beta$-лактамы + тетрациклины + хинолоны + нитрофураны & $5(4,46)$ & \\
\hline & $\beta$-лактамы + тетрациклины + амфениколы + нитрофураны & $1(0,89)$ & \\
\hline & $\beta$-лактамы + аминогликозиды + фторхинолоны + хинолоны & $1(0,89)$ & \\
\hline & Тетрациклины + фторхинолоны + хинолоны + нитрофураны & $12(10,7)$ & \\
\hline & Тетрациклины + фторхинолоны + аминогликозиды + амфениколы & $1(0,89)$ & \\
\hline & Тетрациклины + фторхинолоны + аминогликозиды + нитрофураны & $1(0,89)$ & \\
\hline & Тетрациклины + аминогликозиды + хинолоны + нитрофураны & $1(0,89)$ & \\
\hline & Фторхинолоны + хинолоны +аминогликозиды + нитрофураны & $1(0,89)$ & \\
\hline \multirow[t]{7}{*}{5} & $\beta$-лактамы + тетрациклины + фторхинолоны + хинолоны + нитрофураны & $7(6,25)$ & \multirow[t]{7}{*}{$13(11,6)$} \\
\hline & $\begin{array}{c}\beta \text {-лактамы }+ \text { тетрациклины }+ \text { фторхинолоны }+ \text { аминогликозиды }+ \\
+ \text { нитрофураны }\end{array}$ & $1(0,89)$ & \\
\hline & $\beta$-лактамы + тетрациклины + фторхинолоны + амфениколы + нитрофураны & $1(0,89)$ & \\
\hline & $\beta$-лактамы + тетрациклины + хинолоны + сульфаниламиды + нитрофураны & $1(0,89)$ & \\
\hline & $\begin{array}{c}\beta \text {-лактамы + тетрациклины }+ \text { аминогликозиды }+ \text { сульфаниламиды }+ \\
+ \text { нитрофураны }\end{array}$ & $1(0,89)$ & \\
\hline & $\beta$-лактамы + аминогликозиды + фторхинолоны + хинолоны + нитрофураны & $1(0,89)$ & \\
\hline & Тетрациклины + амфениколы + фторхинолоны + хинолоны + нитрофураны & $1(0,89)$ & \\
\hline \multirow[t]{4}{*}{6} & $\begin{array}{c}\beta \text {-лактамы + тетрациклины + аминогликозиды }+ \text { фторхинолоны }+ \\
+ \text { сульфаниламиды }+ \text { нитрофураны }\end{array}$ & $2(1,78)$ & \multirow[t]{4}{*}{$10(8,9)$} \\
\hline & $\begin{array}{c}\beta \text {-лактамы + тетрациклины + аминогликозиды }+ \text { фторхинолоны + } \\
+ \text { аминогликозиды + нитрофураны } \\
\end{array}$ & $4(3,57)$ & \\
\hline & $\begin{aligned} \beta \text {-лактамы } & + \text { тетрациклины }+ \text { фторхинолоны }+ \text { хинолоны }+ \\
& + \text { сульфаниламиды нитрофураны }\end{aligned}$ & $3(2,68)$ & \\
\hline & $\begin{array}{c}\text { Тетрациклины + фторхинолоны + хинолоны }+ \text { амингликозиды }+ \\
+ \text { сульфаниламиды }+ \text { нитрофураны }\end{array}$ & $1(0,89)$ & \\
\hline 7 & $\begin{array}{c}\beta \text {-лактамы + тетрациклины + амфениколы }+ \text { фторхинолоны }+ \text { хинолоны }+ \\
+ \text { сульфаниламиды }+ \text { нитрофураны }\end{array}$ & $1(0,89)$ & $1(0,89)$ \\
\hline 8 & $\begin{array}{c}\beta \text {-лактамы + тетрациклины + амфениколы }+ \text { фторхинолоны + хинолоны }+ \\
+ \text { аминогликозиды }+ \text { сульфаниламиды }+ \text { нитрофураны }\end{array}$ & $1(0,89)$ & $1(0,89)$ \\
\hline
\end{tabular}

В общей сложности было изучено 45 различных моделей антибиотикорезистентности, из них 16 изолятов были устойчивы только к одной группе антибактериальных препаратов, 17 изолятов - к двум группам, 22 - к трем, 32 - к четырем, 13 - к пяти, 10 - к шести, 1 - к семи и 1 - к восьми группам (табл. 3). Изоляты, устойчивые к шести и более группам антибактериальных препаратов, принимали как экстремально резистентные изоляты. Большинство изолятов были резистентны к 3-4 группам антибактериальных препаратов.

При этом наиболее частой моделью антибиотикорезистентности была модель «тетрациклины + фторхинолоны + хинолоны + нитрофураны» -12 изолятов, «нитрофураны» -9 изолятов, «фторхинолоны + хинолоны + нитрофураны» -8 изолятов, « $\beta$-лактамы + тетрациклины + фторхинолоны + хинолоны + нитрофураны» -7 изолятов. Подобная картина наблюдалась при исследовании сальмонелл, изолированных в Корее [17], Китае [18]. Препараты данной группы чаще всего используют для лечения энтеропатогенных инфекций. Следует отметить, что препараты группы фторхинолонов являются «критическим важными антибиотиками» для лечения заболеваний, вызванных сальмонеллами. Препараты групп хинолонов и цефалоспоринов также входят в список ВОЗ как критически важные для медицины [10]. Уровень резистентности к антибактериальным препаратам групп бета-лактамов был ниже по сравнению 
с исследованиями ряда авторов, в частности [19], что, в свою очередь, может быть связано с использованием различных препаратов, а также их дозировкой.

Таким образом, в результате проведенных исследований в основном были выделены изоляты, относящиеся к серотипам $S$. enteritidis и S. typhymurium.

Преобладающее количество изолятов были резистентны к таким препаратам, как фурадонин (группа нитрофуранов), тетрациклин (группа тетрациклинов), налидиксовой кислоте (группа хинолонов).

Все изоляты были чувствительны к препарату гентамицину (группа аминогликозидов).

Исследования показали наличие 45 различных моделей антибиотикорезистентности, среди которых наиболее распространенной являлась модель «тетрациклины + фторхинолоны + хинолоны + нитрофураны».

Полученные результаты свидетельствуют о потенциальной возможности распространения резистентности среди штаммов сальмонелл к препаратам, являющимся критически важными для лечения животных и человека. Антибиотикорезистентность штаммов сальмонелл является результатом практически повсеместного нерационального использования ветеринарными специалистами антибактериальных препаратов. Уровень антибиотикорезистентности штаммов сальмонелл, выявленный в Северном регионе Казахстана, является серьезной проблемой, требующей постоянного контроля и проведения мероприятий по сдерживанию развития и распространения антибиотикорезистентности бактерий как на местном, так и на республиканском уровнях.

Работа выполнена по научно-технической программе Министерства сельского хозяйства Республики Казахстан BR10764944 «Разработка методов аналитического контроля и проведения мониторинга безопасности пищевой продукции» на 2021-2023 гг.

\section{БИБЛИОГРАФИЧЕСКИЙ СПИСОК}

1. Supplement 2008-2010 (no. 48) to the White-Kauffmann-Le Minor scheme / S. IssenhuthJeanjean, P. Roggentin [et al.] // Research in Microbiology. - 2014. - Vol. 165, Is. 7. - P. 526-530. https://doi.org/10.1016/j.resmic.2014.07.004.

2. Серологические свойства и антибиотикорезистентность изолятов бактерий рода Salmonella, выделенных из сырья животного происхождения / C.Е. Шмайхель, Н.Б. Шадрова, Е.С. Ерофеева, С.И. Данильченко // Ветеринария сегодня. - 2019. - № 4 (31). - С. 25-30. - DOI: 10.29326/2304-196X-2019-4-31-25-30.

3. Diversity of Antimicrobial Resistance Phenotypes in Salmonella Isolated from Commercial Poultry Farms / K.A. Liljebjelke, C.L. Hofacre, D.G. White [et al.] // Frontiers in Veterinary Science. 2017. - Vol. 4. - P. 96. - DOI:10.3389/fvets.2017.00096.

4. Antibiotic Use in Agriculture and Its Consequential Resistance in Environmental Sources: Potential Public Health Implications / C. Manyi-Loh, S. Mamphweli, E. Meyer, A. Okoh // Molecules. 2018. - Vol. 23. - P. 795. - https://doi.org/10.3390/molecules23040795.

5. Global trends in antimicrobial use in food animals / T.P. Van Boeckel, C. Brower, M. Gilbert [et al.] // Proceedings of the National Academy of Sciences May. - 2015. - Vol. 112 (18). - P. 56495654. - DOI: 10.1073/pnas.1503141112.

6. MУ 4.2.2723-10. Лабораторная диагностика сальмонеллезов, обнаружение сальмонелл в пищевых продуктах и объектах окружающей среды: метод. указания. - М.: ФЦГиЭ Роспотребнадзора, 2011. - Введены с 02.09.2010.

7. Investigating deep phylogenetic relationships among cyanobacteria and plastids by small subunit rRNA sequence analysis / S. Turner, K.M. Pryer, V.P. Miao, J.D. Palmer // J. Eukaryot Microbiol. - 1999. - Vol. 46(4). - P. 327-338. 
8. Global patterns of $16 \mathrm{~S}$ rRNA diversity at a depth of millions of sequences per sample / G. Caporaso, C.L. Lauber, W.A. Walters [et al.] // PNAS. - 2011. - Vol. 108 (Suppl. 1). - P. 45164522. - https://doi.org/10.1073/pnas.1000080107.

9. МУК 4.2.1890-04. Определение чувствительности микроорганизмов к антибактериальным препаратам: метод. указания. - М.: ФЦГиЭ Роспотребнадзора, 2004. - Введены c 04.03.2004.

10. European Committee on Antimicrobial Susceptibility Testing Breakpoint tables for interpretation of MICs and zone diameters Version 9.0, valid from 2019-01-01. - P. 96.

11. CLSI M100-ED29: Performance Standards for Antimicrobial Susceptibility Testing, 29th Edition. - Wayne, PA: Clinical and Laboratory Standards Institute, 2019.

12. Occurrence and Characterization of Salmonella Isolated from Large-Scale Breeder Farms in Shandong Province, China / Jie Yang, Siwei Gao, Yajie Chang [et al.] // BioMed Research International. - 2019. - Article ID 8159567. - 8 p. - https://doi.org/10.1155/2019/8159567.

13. Prevalence and antibiotic resistance of Salmonella enteritidis and Salmonella typhimurium in raw chicken meat at retail markets in Malaysia / T.Y. Thung, N.A. Mahyudin, D.F. Basri [et al.] // Poultry Science. - 2016. - Vol. 95, Is. 8. - P. 1888-1893. - DOI: https://doi.org/10.3382/ps/pew144.

14. Characterisation of antimicrobial resistance patterns and class 1 integrons among Escherichia coli and Salmonella enterica serovar Choleraesuis strains isolated from humans and swine in Taiwan / Shu-Chen Hsu, Tsai-Hsin Chiu, Jen-Chieh Pang [et al.] // International Journal of Antimicrobial Agents. - 2006. - Vol. 27, Is. 5. - P. 383-391. - https://doi.org/10.1016/j.ijantimicag.2005.11.020.

15. Serovar distribution, antimicrobial resistance profiles, and PFGE typing of Salmonella enterica strains isolated from 2007-2012 in Guangdong, China / B. Ke, J. Sun, D. He [et al.] // BMC Infect Dis. - 2014. - Vol. 14. - P. 338. - https://doi.org/10.1186/1471-2334-14-338.

16. Nair V.T. Divek, Venkitanarayanan Kumar, Kollanoor Johny Anup. Antibiotic-Resistant Salmonella in the Food Supply and the Potential Role of Antibiotic Alternatives for Control // Foods 7. - 2018. - N 10. - P. 167. - https://doi.org/10.3390/foods7100167.

17. Antibiotic Resistance Patterns and Serotypes of Salmonella spp. Isolated at Jeollanam-do in Korea / K.B. Yoon, B.J. Song, M.Y. Shin [et al.] // Osong public health and research perspectives. 2017. - Vol. 8(3). - P. 211-219. - https://doi.org/10.24171/j.phrp.2017.8.3.08.

18. Occurrence, antimicrobial resistance and biofilm formation of Salmonella isolates from a chicken slaughter plant in China / Huhu Wang, Keping Ye, Xinru Wei [et al.] // Food Control. 2013. - Vol. 33, Is. 2. - P. 378-384. - https://doi.org/10.1016/j.foodcont.2013.03.030.

19. Prevalence and antimicrobial resistance of Salmonella enterica subspecies enterica serovar Enteritidis isolated from broiler chickens in Shandong Province, China, 2013-2018 / Xin Yu, Hongwei Zhu, Yongheng Bo [et al.] // Poultry Science. - 2021. - Vol. 100, Is. 2, - P. 1016-1023. - https://doi. org/10.1016/j.psj.2020.09.079.

\section{REFERENCES}

1. Issenhuth-Jeanjean S., Roggentin P., Matthew M., Guibourdenche M., Elizabeth de Pinna, Satheesh Nair, Patricia I Fields, François-Xavier Weill, Research in Microbiology, 2014, Vol. 165, Is. 7, P. 526-530, https://doi.org/10.1016/j.resmic.2014.07.004.

2. Shmajhel' S.E., Shadrova N.B., Erofeeva E.S., Danil'chenko S.I., Veterinariya segodnya, 2019, No. 4 (31), pp. 25-30. (In Russ.)

3. Liljebjelke K.A., Hofacre C.L., White D.G., Ayers S., Lee Margie D., Maurer J.J., Frontiers in Veterinary Science, 2017, Vol. 4, P. 96, DOI:10.3389/fvets.2017.00096.

4. Manyi-Loh C., Mamphweli S., Meyer E., Okoh A., Molecules, 2018, Vol. 23, P. 795, https:// doi.org/10.3390/molecules23040795. 
5. Thomas P. Van Boeckel, Charles Brower, Marius Gilbert, Bryan T. Grenfell, Simon A. Levin, Timothy P. Robinson, Aude Teillant, and Ramanan Laxminarayan, Proceedings of the National Academy of Sciences May, 2015, Vol. 112 (18), P. 5649-5654, DOI: 10.1073/pnas.1503141112.

6. MU 4.2.2723-10. Laboratornaya diagnostika sal'monellezov, obnaruzhenie sal'monell $v$ pishchevyh produktah i ob"ektah okruzhayushchej sredy (Laboratory diagnostics of salmonellosis, detection of salmonella in food products and environmental objects), Moscow: FCGiE Rospotrebnadzora, 2011.

7. Turner S., Pryer K.M., Miao V.P., Palmer J.D., J. Eukaryot Microbiol, 1999, Vol. 46 (4), P. 327-338.

8. Gregory Caporaso, Christian L. Lauber, William A. Walters, Donna Berg-Lyons, Catherine A. Lozupone, Peter J. Turnbaugh, Noah Fierer, and Rob Knight, PNAS, 2011, Vol. 108 (Suppl. 1), P. 4516-4522, https://doi.org/10.1073/pnas.1000080107.

9. MUK 4.2.1890-04. Opredelenie chuvstvitel'nosti mikroorganizmov $k$ antibakterial'nym preparatam (Determination of the sensitivity of microorganisms to antibacterial drugs), Moscow: FCGiE Rospotrebnadzora, 2004.

10. European Committee on Antimicrobial Susceptibility Testing Breakpoint tables for interpretation of MICs and zone diameters Version 9.0, valid from 2019-01-01, 96 p.

11. CLSI M100-ED29: Performance Standards for Antimicrobial Susceptibility Testing, 29th Edition, Wayne, PA: Clinical and Laboratory Standards Institute, 2019.

12. Jie Yang, Siwei Gao, Yajie Chang, Mingliu Su, Yutong Xie, Shuhong Sun, BioMed Research International, 2019, Article ID 8159567, 8 p, https://doi.org/10.1155/2019/8159567.

13. Thung T.Y., Mahyudin N.A., Basri D.F., Wan Mohamed Radzi C.W.J., Nakaguchi Y., Nishibuchi M., Radu S., Poultry Science, 2016, Vol. 95, Is. 8, P. 1888-1893, DOI: https://doi. org/10.3382/ps/pew144.

14. Shu-Chen Hsu, Tsai-Hsin Chiu, Jen-Chieh Pang, Chao-Hsiu Hsuan-Yuan, Gan-Nan Chang, Hau-Yang Tsen, International Journal of Antimicrobial Agents, 2006, Vol. 27, Is. 5, R. 383-391, https://doi.org/10.1016/j.ijantimicag.2005.11.020.

15. Bixia Ke, Jiufeng Sun, Dongmei He, Xiaocui Li, Zhaoming Liang, Chang-wen Ke, $B M C$ Infect Dis, 2014, Vol. 14, P. 338, https://doi.org/10.1186/1471-2334-14-338.

16. Nair V.T. Divek, Venkitanarayanan Kumar, Kollanoor Johny Anup, Foods 7, 2018, No. 10, P. 167, https://doi.org/10.3390/foods7100167.

17. Ki-Bok Yoon, Byung-Joon Song, Mi-Yeong Shin, Hyun-Cheol Lim, Yeon-Hee Yoon, DooYoung Jeon, Hoon Ha, Soo-In Yang, Jung-Beom Kim, Osong public health and research perspectives, 2017, Vol. 8 (3), P. 211-219, https://doi.org/10.24171/j.phrp.2017.8.3.08.

18. Huhu Wang, K. Ye, Xinru Wei, Jinxuan Cao, X. Xu, Guanghong Zhou, Food Control, 2013, Vol. 33, Is. 2, P. 378-384, https://doi.org/10.1016/j.foodcont.2013.03.030.

19. Xin Yu, Hongwei Zhu, Yongheng Bo, Youzhi Li, Yue Zhang, Yang Liu, Jianlong Zhang, Linlin Jiang, Guozhong Chen, Xingxiao Zhang, Poultry Science, 2021, Vol. 100, Is. 2, P. 1016-1023, https://doi.org/10.1016/j.psj.2020.09.079. 